\title{
Risk Factors for the Development of BK Virus Infection in Kidney Transplant Recipients in Guilan Province during 2007-2015
}

\section{Masoud Khosravi ( $\nabla$ drmasoudkhosravi@gmail.com )}

1- Associate Professor of nephrology, Urology Research Center, Razi Hospital, School of Medicine, Guilan University of Medical Sciences, Rasht, Iran https://orcid.org/0000-0002-7495-4937

\section{Mahlagha Dadras}

2- M.D., Urology Research Center, Razi Hospital, School of Medicine, Guilan University of Medical Sciences, Rasht, Iran

\section{Ali Monfared}

3- Professor of nephrology, Urology Research Center, Razi Hospital, School of Medicine, Guilan University of Medical Sciences, Rasht, Iran https://orcid.org/0000-0002-5231-1658

\section{Siamak Granmaieh}

4- Pathologist, worked in private lab, all urine sample examined by him.RIP

\section{Mohammad Shenagari Rashti}

5- Associate Professor of Medical Virology, Department of Medical Microbiology, School of Medicine, Guilan University of Medical Sciences Rasht, Iran https://orcid.org/0000-0003-4221-8748

\section{Soheil Soltanipour}

6- Associate Professor of Community Medicine, Department of Community Medicine, Eye Research Center, Guilan University of Medical Sciences. Rasht, Iran https://orcid.org/0000-0001-7768-1121

\section{Research Article}

Keywords: BK virus; Decoy cell; JC virus; polyomavirus infection; renal transplantation; risk factors

Posted Date: May 5th, 2020

DOI: https://doi.org/10.21203/rs.3.rs-27114/v1

License: (9) This work is licensed under a Creative Commons Attribution 4.0 International License. Read Full License 


\section{Abstract}

Purpose: Polyomavirus nephropathy has been recognized as an important cause of silent loss of kidney transplant function in 3-5\% of kidney transplant recipients. We evaluate the risk factors associated with BK virus infection in our kidney transplant recipients.

Materials and Methods: We collected clinical information, urinary Decoy cell, and blood PCR tests for polyomavirus infection in our 223 kidney transplant recipients undergoing surgery at Razi hospital at Guilan University of Medical Sciences between 2007 and 2015. In case of high virus count or if plasma creatinine was elevated, a kidney biopsy would be performed. SPSS version 18 were used for analysis of data.

Results: Among 223 patients, 116 (52\%) were male, 107 females (48\%). Mean age of participants were 49.6 years. Of 223 kidney transplant patients enrolled in this study, 41 (18.3\%) had viral genome in their urine, and of these 41 patients, 15 persons (6.7\%) had viral genome in their blood. Only 3 patients out of 10 , have had BK Virus nephropathy in their kidney biopsy. Among risk factors, we found that posttransplant duration, and use of anti-thymocyte globulin, were most significant risk factors for finding Decoy cells in urine of patients $(p<0.01)$.

Conclusions: Post-transplant time, specially the first 6 months because of strong immunosuppression, and thereafter, use of anti-thymocyte globulin (for prophylaxis or treatment of rejection) were recognized as most important risk factors for reactivation of polyomavirus infection in our patients. We concluded that kidney transplant recipients should be monitored in episodically after transplant.

\section{Introduction}

BK polyomavirus (BKV) is a non-enveloped double- stranded DNA virus, that is a member of polyoma subgroup of papova viruses, which includes JC virus and SV40.

Infection with BK virus is common in the general population, with estimates of seropositivity in adults of $80 \%-90 \%[1,2]$. After resolution of primary infection, BK virus remain latent in several locations throughout the body, most notably within the genitourinary system [3]. During times of immunosuppression, the virus may become activated and begin to replicate $[4,5]$.

After introduction of potent immunosuppressive medications in late 1990s, up to one-half of renal allograft recipients exhibit BK virus viruria within the 1 st few months [6,7], but only $10 \%-15 \%$ develop viremia [3]. Progression to viremia is thought to be a requisite event before the development of BK virus nephropathy (BKVN) [2], about 3\%-5\% of allografts were being lost due to BKVN.

Transplant kidney biopsy remains the gold standard for diagnosing BKV nephropathy [8].

There is no definite treatment for BKV infection including: BKV nephropathy. [8, 9] 
Studies that search for risk factors responsible for BKVN have shown inconclusive results [9]. In order to identify risk factors for BKVN, we studied patients in our center who received kidney transplants from 2007-2015.

\section{Materials And Methods}

This is a descriptive, retrospective, cross sectional single center study. 223 adult kidney transplant (kidney TX) patients that they have done their surgery in our hospital (Razi hospital, Guilan University of Medical Sciences, Rasht, Iran) since October 2007 to September 2015, have been enrolled in this study. All patients gave their informed written consents to participate. The goal of this study was to evaluate the impact of the following elements as the risk factors associated with the advent of polyomavirus infection in kidney TX recipients: age, gender, blood group, BMI, length of time of kidney TX, level of sCr and GFR during detection of Decoy cell, length of time on HD before kidney TX, etiology of ESRD, duration of having stent after kidney transplant, type of immunosuppressive drugs used for induction and maintenance therapy, Hepatitis B and C, CMV infection association, DM involvement before and after kidney TX, rejection prophylaxis by MP pulse and ATG, maintenance immunosuppressive therapy by cyclosporine, tacrolimus, mycophenolate mofetile, sirolimus.

All the patients received MP pulse (500-1000mg/ day, for 1-3days), and ATG (1 mg kg/ day, for 7 days, cumulative dose:350- $400 \mathrm{mg}$ ) as induction therapy starting in operating room and after surgery.

Maintenance immunosuppressive drugs were: prednisolone (5-7.5 mg/day with breakfast), cyclosporine (trough level 100-150ng/ml), tacrolimus (trough level 5-8 $\mathrm{ng} / \mathrm{ml}$ ), sirolimus (trough level 6-10 $\mathrm{ng} / \mathrm{ml}$ ), and mycophenolate mofetil (1000- $2000 \mathrm{mg} /$ day before meal). All kidney transplant recipients received live kidney donation.

Evaluation has been began with finding of decoy cell (even one) in urine every month at first six months post-transplant and then every other months, [Urine cytology smears was stained using Papanicolaou method were evaluated for the presence of cells with intranuclear viral inclusions (decoy cells, which were counted (number per 10 high-power fields)]. We perform measuring viral load of BK- JC virus DNA RTPCR in blood and urine in case of increase of plasma creatinine level or if decoy cell in urine cytology repeatedly was found. All lab tests were done in one lab.

If the $\mathrm{sCr}$ was normal, we just reduce the dose of immunosuppressive drugs, and follow the patient regularly, otherwise $\mathrm{SCr}$ was increased we did a kidney TX biopsy. Due to high costs of both BK-JC virus DNA RT-PCR measurement and kidney biopsy, some patients did not accept to do such tests because their insurance didn't cover the expenses.

\section{Statistical analysis}

All collecting data were analyzed by SPSS version 18 software. According to the type of variables, we used descriptive statistics, mean, and standard deviation (SD). Since distribution of BMI values based on 
Klomogorov- smirnova and shapiro-wilktests in both kidney TX groups in terms of the status of decoy cell in the urine( positive or negative) followed a normal distribution, therefore, to compare the mean of BMI in two group, we used independent T- test. Because the duration of the transplant variable and the values of GFR in both groups do not follow the normal distribution, therefore, the non- parametric U Mann Whitney test was used to compare the mean transplantation time. Parameters were considered meaningful if Pvalue was $<0.05$.

\section{Results}

223 adult kidney TX recipients have undergone their kidney TX surgery in our hospital since October 2007 to September 2015, 116 recipients (52\%) were male, and 107(48\%) female. The youngest and oldest recipient was 17 and 79-year-old, respectively. Minimum and maximum time of detection of decoy cell in urine of recipients of kidney transplant was 1 and 26 months respectively, with an average of $10.90 \pm 5.62$ months. Of 223 participants in this study, 41 patients (18.3\%) had viral genome in their urine, and 15 out of $41(6.7 \%)$ have had viral genome in their blood.

No significant relationship was found between age of kidney TX recipients, sex, blood groups and etiology of ESRD with BK-JC virus infection.

Kolmogorov-Smirnova test for distribution of BMI showed that in both groups of patients with or without decoy cell in their urine [(26 \pm 4.02$)(27 \pm 5.02)$ respectively], BMI follows the normal distribution. Comparison of BMI in both groups of patients by Two Independent t test showed no meaningful differences between them.

Shapiro-wilk test in both groups of transplant patients with or without decoy cell in their urine, showed that duration of transplantation time variable in both groups doesn't follow normal distribution.

Comparison of duration of post transplantation time in both group (positive and negative urine decoy cell) by Mann-Whitney $U$ test showed there is a meaningful difference between them (7 months in recipients with positive decoy cell, 12 months in recipients with negative decoy cell in urine). $(P<0.001)$

No meaningful relation between rejection and initiation of dialysis in transplant patients with BK-JC virus was found.

Average and SD of Plasma creatinine $(1.3 \pm 0.65 \mathrm{mg} / \mathrm{dl})$, and GFR with $(61 \pm 2.09 \mathrm{ml} / \mathrm{min})$ or without $(59 \pm 2.45 \mathrm{ml} / \mathrm{min})$ decoy cell in urine respectively showed no meaningful statistical difference.

Comparison of duration of dialysis time before transplantation in patients with or without decoy cell in urine [(12.88 \pm 11.99 months) (16.91 \pm 18.75 months) respectively] by Mann-Whitney U test showed no meaningful differences.

Statistical analysis showed no meaningful correlation between positive urine decoy cell and infection by hepatitis $B$ and $C, D M$, and CMV infection. 
Chi-square test showed no correlation between positive urine decoy cell and corticosteroid pulse induction (1-3 gram) during kidney TX.

Fisher's-Exact test showed a meaningful correlation between positive urine decoy cell and thymoglobulin injection ( $p=0.001)$, and odds ratio calculation was (6.55), Table 1 .

No association was found between the type of immunosuppressive drug regimen (tacrolimus, cyclosporine, mycophenolate mofetile, sirolimus) and positive decoy cell in urine Table 1.

In almost all of our patients, we removed ureteral stent after one month, no ureteral stricture was found. Although nearly all the recipients and donors in this study were HLA mismatch, but this was not statistically significant for emerging of decoy cell in urine. Recipients and donors were all negative for finding "Decoy Cell" in urine before kidney transplant.

Urinalysis in our patients with decoy cell in their urine was interestingly normal.

Cold ischemic time was less than 1 hours. CMV serostatus in all donors and recipients were positive just for lgG.

\section{Discussion}

The human BK polyomavirus is associated with two significant complications in transplant recipients: PyVAN in $1-10 \%$ of kidney transplant recipients and PyVHC in 5-15\% of HSCT patients [10-11-12].

Although JCV inhabits in the uroepithelium [13], and during periods of immunosuppression may reactivate [14], it rarely causes nephropathy [15].

After kidney transplantation, in state of immunosuppression BKV replication starts and progresses through detectable stages: Viruria then viremia then nephropathy [16]. Although there are different screening tests for finding BKV infection, with regards to Hirsch and Randhawa in their paper (Figure 1 in reference 10), we have chosen to find decoy cell in urine as screening test because it is less expensive and insurance covers it. Figure 1 shows "decoy cell" taken in our lab.

Of 223 participants in this study, 41 patients (18.3\%) had viral genome in their urine, and of these 41 patients, $15(6.7 \%)$ have had viral genome in their blood.

Only 10 patients agreed to have a kidney biopsy, of which only 3 reported BKV Nephropathy.

Vera in Spain showed positive PCR in $75 \%$ of urine and $33 \%$ in plasma of kidney TX patients [17]. Study by Bohl in 2007, showed viral genome in urine of $44 \%$ of patients [16].

In our study the incidence of BKV in men and women was $5.2 \%, 10.3 \%$ respectively, also the incidence of $\mathrm{JC}$ virus in men was $10.3 \%$, and in women was $6.5 \%$, and in those patients the incidence of finding BK 
and $\mathrm{JC}$ virus together in their urine in men and women was $1.7 \%$, and $2.8 \%$ respectively. In our study no statistically, meaningful relationship was seen between sex and BK, JC virus.

In a retrospective study of 880 kidney transplant patients by Prince et al in 2008, male sex was reported as main risk factor for the virus [18].

Average age in our patients was $49.57 \pm 13.48$ years old. There was no correlation between age and decoy cell in urine of our patients. Nevo in 1998 showed similar finding [19]. Ramos found that age has a correlation with finding BK- JC Virus in renal transplant recipients (P0.003) [20]. Average sCr in our patients with decoy cell in their urine was $1.3 \mathrm{mg} / \mathrm{dl}$, we haven't found any significant increases in plasma creatinine. In our study the incidence of CMV (IgG positive and IgM negative) was $97.6 \%$ in those patients that have decoy cell in their urine, but it was $6 \%$ in patients who haven't decoy cell in their urine. In study done by Theodoropoulos in 2012, incidence of CMV in patients which were negative for BK virus was $8.5 \%$, but in those with viruria, viremia, and those with BKVN, CMV was found in 12.4, 21.3, and $32.3 \%$ respectively [21].

In our study average BMI in patients with positive urine decoy cell was $26.4 \pm 4$

But in those with negative urine decoy cell, it was $27.1 \pm 5$. This calculation showed no statistically meaningful relation between BMI and urine decoy cell. In some studies BMI was considered as a risk factor. Perez in 2009 showed that BMI more than 25 must considered as a risk factor [22]. Obesity may predispose to infection through creation of a pro-inflammatory state with blunting of the immune response at both the humoral and cellular levels, as well as generalized tissue hypoperfusion leading to decreased tissue oxygen tension [22]. Increased weight may also cause inconsistencies of immunosuppressant drug levels and longer operation time, resulting in prolonged graft ischemia and delayed graft function [22].

No correlation was found between kidney TX recipient's blood group and BKV infection, all our patients were $A B O$ compatible, googling for this showed no results except for blood group incompatible [23]. No significant correlation was found between hepatitis $C$ and $B$ and BK viruria in our study. Dheir et al showed positive correlation between BK Virus nephropathy and Hepatitis B virus positivity [24]. Relation between immunosuppressive drugs (cyclosporine, tacrolimus, mycophenolate mofetil, sirolimus, and antithymocyte globulin) used for our patients and urine decoy cell, showed statistically significance correlation between anti-thymocyte globulin use and positive urine decoy cell $(p=0.001)$. (Table 1)

In fact, those patients who received anti-thymocyte globulin showed 6.5 times more than other patients decoy cell in their urine. This finding was consistent with study done by Oliver prince in 2008 [18].

Bernnan in 2004 showed a positive correlation between viruria and tacrolimus (in $46 \%$ of 200 renal transplant recipients), but only $13 \%$ in those who received cyclosporine, (P 0.005) [6].

Average duration post-transplant in our patients that showed decoy cell in their urine was $10.90 \pm 5.62$ months. In group with positive urine decoy cell it was calculated 7 months and those with negative urine 
decoy cell 12 months, this was statistically meaningful $(p=0.01)$.

This result means that with regard to intense immunosuppression during first months post kidney transplantation, most decrease in immunity would be happen at that time that could result in reactivation of latent virus. In study by saundh in 2010, different patterns of reactivation were observed: BK viruria was detected after 3-6 months, and JC viruria was observed as early as 5 days post-transplantation [25].

In our study, 9 out of 223 patients had DM, 3 of them (7.3\%) had positive urine decoy cells that it was not significantly meaningful. This was consistent with lopez finding [26].

No correlation was found between kidney TX rejection and polyomavirus infection in our study, because only four patients had acute rejection, one of them was jc positive. Christopher in 2003 by his study showed no correlation between rejection and polyomavirus infection [27].

In our study average GFR in patients with positive, and negative decoy cell was $61 \pm 2.09,59 \pm 2.45 \mathrm{ml} / \mathrm{min}$ respectively, that was not statistically significant.

Haung also showed this finding [28].

In our study, average duration on dialysis before kidney TX for patients with positive and negative urine decoy cell was $12.88 \pm 11.99$ and $16.91 \pm 18.75$ months respectively, which is not meaningful statistically. Girmaneva et al, found that Compared to-the control group, patients with viruria $>10^{7}$ were treated longer by dialysis and had impaired graft function one-year post transplantation. $(P<0.05)[29]$.

\section{Conclusion}

Polyomavirus infection is a serious threat to life of transplanted kidney. It could be occurring at any time post transplantation. It gradually causes increase in plasma creatinine level silently, and finally may lead to irreversible tubulointerstitial changes in transplanted kidney and then loss of graft [16].

Polyomavirus-associated nephropathy is associated with high viruria levels $\left(>1 \times 10^{7} \mathrm{copies} / \mathrm{ml}\right)$ and lower levels of viremia $\left(>1 \times 10^{4} \mathrm{copies} / \mathrm{ml}\right)[25]$.

Kidney biopsy remain the "gold standard" for diagnosing and managing BKVN [8]. There is no definite treatment for BKV nephropathy [30].

In our study, of 223 participants, $18.3 \%$ have had viral genome in their urine and $6.7 \%$ in their plasma. In our study we found that first few months post kidney TX and use of Anti-thymocyte globulin were highly considered as risk factors for polyomavirus infection.

\section{Declarations}

Acknowledgments: 
Special thanks to research center colleagues, who help us to collect data, and print the article.

\section{Authors' contributions:}

Masoud Khosravi: Design this study and provide most of the data, and wrote the manuscript.

Ali Monfared: reviewed and finalized the manuscript.

Mahlagha Dadras: collect data from clinical files and provide references.

Mohammad Shenagari: Viral PCR tests was done under supervision by him.

Siamak Granmaieh, RIP: urine evaluation for Decoy cell was done by him.

Soheil soltanipour: statistical analysis was done by him.

All authors: Masoud Khosravi, Mahlagha Dadras, Ali Monfared, Siamak Granmaieh, Mohammad Shenagari,

Soheil Soltanipour, reviewed and approved the manuscript.

\section{Medical Ethics Code:}

All data collection and procedures performed in this study were in accordance with the ethical standards of our institution. Code number: IR.GUMS.REC.1930596701

\section{Declaration of conflicting of interests:}

The authors: Masoud Khosravi, Mahlagha Dadras, Ali Monfared, Siamak Granmaieh, Mohammad Shenagari rashti, Soheil Soltanipour, declared that they have no conflicts of interest with respect to the research and authorship of this publication.

\section{Funding:}

The authors: Masoud Khosravi, Mahlagha Dadras, Ali Monfared, Siamak Granmaieh, Mohammad Shenagari rashti, Soheil Soltanipour, received no financial support for this article.

\section{References}

1. Stolt A, Sasnauskas K, Koskela P, et al. Seroepidemiology of the human polyomaviruses. J Gen Virol. 2003; 84:1499- 504.

2. Hirsch HH, Knowles W, Dickenmann M, et al. Prospective study of polyomavirus type BK replication and nephropathy in renal transplant recipients. N Engl J Med. 2002; 347:488-496.

3. Wiseman AC. Polyomavirus nephropathy: a current perspective and clinical considerations. Am J Kidney Dis. 2009; 54:131-42. 
4. Hirsch HH, Steiger J. Polyomavirus BK. Lancet Infect Dis. 2003;3:611-23

5. Boubenider S, Hiesse C, Marchand S. Post transplantationpolyomavirus infection. J Nephrol 1999; 12:24-9.

6. Brennan DC, Agha I, Bohl DL, et al. Incidence of BK with tacrolimus versus cyclosporine and impact of preemptive immunosuppression reduction. Am J Transplant 2005; 5:58-94.

7. Bressollette-Bodin C, Coste-Burel M, Hourmant M, et al. A prospective longitudinal study of BK virus infection in 104 renal transplant recipients. Am J Transplant 2005; 5:1926-33.

8. Deirdre Sawinski and Simin Goral. BK virus infection: an update on diagnosis and treatment. Nephrol Dial Transplant. 2015; 30: 209-217. doi: 10.1093/ndt/gfu023.

9. Pai, D.M. Mann, A. Malik, D. R. Hoover, B. Fyfe, and R.A. Mann. Risk Factors for the Development of BK Virus Nephropathy in Renal Transplant Recipients. Transplantation Proceedings 2015; 47:24652469.

10. H. Hirsch, P. Randhawa and the AST Infectious Diseases Community of Practice. BK Polyoma Virus in Solid Organ Transplantation. American Journal of Transplantation 2013; 13: 179-188. doi:10.1111/ajt.12110

11. Ramos E, Drachenberg CB, Portocarrero $M$, et al. BK virus nephropathy diagnosis and treatment: Experience at the University of Maryland Renal Transplant Program. Clin Transpl 2002; 143-153.

12. Hirsch HH. Polyoma and Papilloma Virus Infections after Hematopoietic Stem Cell or Solid Organ Transplantation. In: Bowden P, Ljungman P, Snydman DR, eds. Transplant infections. 3rdEd. Philadelphia: Lippincott Williams \& Wilkins; 2010, pp. 465-482.

13. Boldorini R, Veggiani C, Barco D, Monga G: Kidney and urinary tract polyomavirus infection and distribution: Molecular biology investigation of 10 consecutive autopsies. Arch Pathol Lab Med. 2005; 129: 69-73.

14. Randhawa P, Uhrmacher J, Pasculle W, Vats A, Shapiro R, Eghtsead B, Weck K: A comparative study of BK and JC virus infections in organ transplant recipients. J Med Virol. 2005;77: 238-243.

15. Wen MC, Wang CL, Wang M, Cheng CH, Wu MJ, ChenCH, Shu KH, Chang D: Association of JC virus with tubulointerstitial nephritis in a renal allograft recipient. J MedVirol. 2004; 72: 675-678.

16. Daniel L. Bohl, Daniel C. Brennan: BK Virus Nephropathy and Kidney Transplantation. Clin J Am Soc Nephrol. 2007; 2: S36-S46. doi: 10.2215/CJN.00920207.

17. Vera-sempere FJ, Rubio L, Moremo-Garcia A, et al. Polyomavirus Chain Reaction Detection of BK Virus and Monitoring of BK Nephropathy in Renal Transplant Recipients at the University Hospital La Fe. Transplantation Proceedings 2005; 37:3770-3.

18. Prince O, Savic S, Dickenmann M, Steiger J, Bubendorf L, Mihatsch MJ. Risk factors for polyoma virus nephropathy. Nephrol Dial Transplant 2009; 24:1024-33.

19. Nevo S, Swan V, Enger C et al. Acute Bleeding after bone marrow transplantation (BMT), incidence and effect on survival. A quantitative analysis in 1402 patients. Blood 1998; 91: 1469-1477. 
20. Ramos E, Drachenberg CB, Papadimitrious JC et al. Clinical course of Polyoma virus nephropathy in 67 renal transplant patients. J Am Soc Nephrol 2002; 13: 2145-2151.

21. Theodoropoulos $\mathrm{N}$, Wang E, Penugonda $\mathrm{S}$, et al, BK virus replication and nephropathy after alemtuzumab induced kidney transplantation. American journal of transplantation 2013; 13: 197-206

22. Perez-Torres, J. Bertran-Pasarell, E. Santiago-Delpín, M. Gonzalez Ramos, et al. Factors and outcome in BK virus nephropathy in a Hispanic kidney transplant population. Transpl Infect Dis 2010; 12: 1622.

23. Hasegawa M, Ito T, Saigo $\mathrm{K}$ et al. Association of DNA amplification in Renal transplant recipients. Transplantation Proceedings 2014; 46: 556-559.

24. Dheir H, Sahin S, Uyar M et al. Intensive polyomavirus nephropathy Treatment as a preferable approach for graft surveillance. Transplantation proceedings 2011; 43: 867-870.

25. Saundh BK, Tibble S, Baker R, Sasnauskas K, Harris M, Hale A. Different pattern of BK and JC polyomavirus reactivation following renal Transplantation. J Clin Pathol. 2010; 63(8):714-8. doi:10.1136/jcp.2009.074864.

26. Lopez, C. Gutierrez, E. Sola, I, et al. Does JC polyomavirus cause nephropathy in renal transplant patients. Transplantation Proceedings, 2010;42: 2889-2891.

27. Christopher K. Buehrig, Donna J. Lager, Mark D. Stegall, et al. Influence of surveillance renal allograft biopsy on diagnosis and prognosis of polyomavirus associated nephropathy. Kidney International, 2003; 64:665-673.

28. Huanga, L. Zhangb, X. Liangc, J. Qiua, et al. Risk Factors for BK Virus Infection and BK Virus associated Nephropathy under the Impact of Intensive Monitoring and Pre-emptive Immunosuppression Reduction Transplantation Proceedings, 2014; 46: 3448-3454.

29. Eva Girmanova, Irena Brabcova, Stepan Bandur, Petra Hribova, et al. A Prospective Longitudinal Study of BK Virus Infection in 120 Czech Renal Transplant Recipients. Journal of Medical Virology, 2011; 83:1395-1400.

30. Caroline Lamarche, Julie Orio, Suzon Collette, Lynne Senécal, et al. BK Polyomavirus and the Transplanted Kidney: Immunopathology and Therapeutic Approaches. Transplantation 2016; 100: 2276-2287.

\section{Table}

Table 1. Frequency of finding Decoy cell in urine by immunosuppressive drugs 


\begin{tabular}{|c|c|c|c|c|c|}
\hline \multicolumn{2}{|l|}{ Drug regimen } & $\begin{array}{l}\text { Urine Decoy cell } \mathrm{N} \\
(\%)\end{array}$ & $\begin{array}{l}\text { No urine Decoy cell } \quad \text { N } \\
\text { (\%) }\end{array}$ & Total & $\begin{array}{l}\text { P- } \\
\text { value }\end{array}$ \\
\hline $\begin{array}{ll}\text { Mycophenolate } & \text { mofetil } \\
\text { Tacrolimus } & \end{array}$ & + & $1(0.4 \%)$ & $18(8.1 \%)$ & $19(8.5 \%)$ & 0.337 \\
\hline $\begin{array}{ll}\text { Mycophenolate } & \text { mofetil } \\
\text { Cyclosporine } & \end{array}$ & + & $30(13.5 \%)$ & $122(54.7 \%)$ & $\begin{array}{c}152 \\
(68.2 \%)\end{array}$ & \\
\hline \multicolumn{2}{|l|}{ Mycophenolate mofetil + Sirolimus } & $7(3.1 \%)$ & $14(6.3 \%)$ & $21(9.4 \%)$ & \\
\hline \multicolumn{2}{|l|}{ Mycophenolate mofetil } & 0 & $3(1.3 \%)$ & $3(1.3 \%)$ & \\
\hline \multicolumn{2}{|l|}{ Sirolimus } & 0 & $5(2.2 \%)$ & $5(2.2 \%)$ & \\
\hline \multicolumn{2}{|l|}{ Cyclosporine } & $3(1.3 \%)$ & $18(8.1 \%)$ & $21(9.4 \%)$ & \\
\hline \multicolumn{2}{|l|}{ Tacrolimus } & 0 & $2(0.9 \%)$ & $2(0.9 \%)$ & \\
\hline \multicolumn{2}{|l|}{ Total } & $41(18.4 \%)$ & $182(81.6 \%)$ & $\begin{array}{c}223 \\
(100 \%)\end{array}$ & \\
\hline \multirow[t]{2}{*}{ Thymoglobulin therapy } & + & $27(90 \%)$ & $70(57.9 \%)$ & $97(64.2 \%)$ & \multirow[t]{2}{*}{0.001} \\
\hline & - & $3(10 \%)$ & $51(42.1 \%)$ & $54(35.8 \%)$ & \\
\hline
\end{tabular}

\section{Figures}


Decoy Cell Taken in our lab.

Page 12/12 